\title{
Finger print Feature Extraction Using Hybrid Approach: QPSO and Bees Algorithms Based on 3D Logistic Map
}

\author{
Noor Hayder Abdul Ameer \\ University of Technology \\ Department of Computer Sciences \\ 110048@uotechnology.edu.iq
}

\begin{abstract}
:
Particle swarm optimization algorithm is easy to access premature convergence in the solution process, and also fall into the local optimal solution. The Bees algorithm is an inference optimization based on the foraging behavior of honey bees. It has been assured that this algorithm is able to search for global optimum, but there is one defect, it's the fact that the global best solution is not used in a direct manner, but the Bees algorithm stores it of each iteration. We propose a new hybrid approach in order to address these problems, it is between Quantum particle swarm optimization and Bees algorithm based on 3D logistic map. On one hand, the 3D logistic map is employed for initializing uniform distributed particles so as to enhance the initial population quality, which is a very efficient yet simple method for improving the quality of initial population. On the other hand, the essence of this approach is the use Quantum particle swarm optimization for optimum fitness value of population in Bees algorithm. After determining the starting point in the new algorithm, the form of distribution is of circles with random angles and random diagonal where 3D logistic map generate the random numbers. The algorithm was applied for extracting the characteristics of the fingerprint, and the results when compared to the traditional particle swarm optimization algorithm were excellent.
\end{abstract}

Keywords: Particle swarm optimization, Bees algorithm, 3D logistic map, Local optimal, Global optimum. 


\section{Introduction}

Natural sciences have been increasingly interested by the computational researchers in the last two decades, and especially biology, as a modeling paradigms source. The conduct of different biological phenomena and entities massively influenced many research areas. It generated the majority of population based let heuristics such as Bees Algorithm (BA), Evolutionary Algorithms (EAs), Particle Swarm Optimization (PSO) etc. Honey bees have been intensively studied. The two algorithms are population-based global search swarm intelligence met heuristics, co-operative.

PSO has experienced a plethora of changes since the beginning of its development. Rules of quantum of mechanics are to note and monitor the conduct of PSO application are one of the recent developments in PSO. Particle Swarm Optimization is named Quantum PSO (QPSO). Some variants of QPSO include mutation based PSO [1], [2], the mutation is applied to the positions of the particle of gbest (the global best) and mbest (the mean best), also, one of the variables of QPSO a perturbation constant referred as Lyapunov constant is added. Nevertheless, to the best of our knowledge the concept of recombination operator in QPSO has not been used.

The paper is organized as follows: Section 2 Related works, in Sections 3 a brief description about basic Particle Swarm Optimization and Bees Algorithm is given, Section 4 described the 3D Logistic map, the proposed algorithm is presented in Section 5, Section 6 will give the experimental results of the proposed algorithm along with a comparison to best results gained from previous works. Finally, in Section 7 we present the conclusions of paper.

\section{Literature Review}

In this section, we will show some of the previous studies about Hybrid Approach between PSO and BA which are close and related to our study.

These studies include the following papers:

1. In [3] (2012), "on the hybridization of the artificial be colony and partial swarm optimization algorithms ". The hybridization technique is a component based one, where, to improve the personal bests of the particles, the PSO algorithm is augmented with an ABC component. The researcher did not exceed the weaknesses of the PSO algorithm.

2. In [4] (2012)," A new hybrid Model of PSO and ABC algorithms for optimization in Dynamic Environment ".

The proposed did not address the local solution.

3. In [5] (2014), "Hybrid artificial Bee colony algorithm and particle swarm search for global optimization". The algorithm is for improving the convergence speed, great point set notion is used rather than random chosen generates the initial, firstly, secondly, instead of to enhancing the power of exploitation, the scouts, harness bee and attendant utilize the mechanism of PSO for searching new nominee solutions. The proposed algorithm did not specify the method of return on arrival in the local optimization.

4. In [6] (2014)," particle swarm optimizationArtificial Bee colony chain (PSOABCC): A Hybrid Metaheuristic Algorithm.". They worked on building a hybrid algorithm that Called (PSOABCC) that repeatedly applied ideas from PSO and ABC algorithm is a loop. In the method presented by the research, the properties extracted as shown to match.

5. In [8] (2012), "Improved swarm Bee algorithm for global optimization". [8]. They have made a difference change in both harness as well as sensor bee phases. In the search, all vulnerabilities are processed for feature extraction algorithm. 


\section{Evolutionary Algorithms}

\subsection{Particle Swarm Optimization}

Particle swarm optimization (PSO) is populationbased optimization method and it is based on the simulating social behaviors of fish schooling or bird flocking. The PSO algorithm is initialized through a set of candidate solutions named a particle. Number of particles $\mathrm{N}$ are moving around in a D-dimensional search space of the problem. At the $i^{\text {th }}$ iteration, the position of the $\mathrm{i}^{\text {th }}$ particle is represented by $(t)=\left(x_{i_{1}}\right.$, $\left.2, \ldots, x_{i \mathrm{D}}\right)$ and $x_{i, n} \in\left[L_{n}, U_{n}\right], 1 \leq n \leq N$ where $L_{n}$ and $U_{n}$ are the lower and upper bound for the $n^{\text {th }}$ dimension, respectively [9]. So far, the best position that has so far been visited by $i^{\text {th }}$ particle is represented as $p_{i}=$ $\left(p_{i 1}, 2, \ldots, p_{i \mathrm{D}}\right)$ which is also called pbest. The global best (gbest) refers to the global best position attained by the whole swarm and represented as $p_{g}=$ $\left(p_{g 1,2}, \ldots, p_{g \mathrm{D}}\right)$. The velocity vector at the $\mathrm{t}^{\text {th }}$ iteration can be represented as $(t)=\left(v_{i 1}, 2, \ldots, v_{i \mathrm{D}}\right)$. At the next iteration, position of the particle and the velocity are calculated according to (1)

$$
\begin{aligned}
& v_{i}(t+1)=w v_{i}(t)+c_{1} r_{1}\left(\text { pbest }_{i}(t)-x_{i}(t)\right)+ \\
& c_{2} r_{2}\left(\text { gbest }_{i}-x_{i}(t)\right) \\
& (t+1)=x_{i}(t)+v_{i}(t)
\end{aligned}
$$

Here, the parameters $c_{1}$ and $c_{2}$ are called acceleration coefficients (usually $c_{1}=c_{2}$ ), $\mathrm{w}$ is called inertia weight, it is set to 1 in the original PSO [9]. $r_{1}$ and $r_{2}$ are random numbers in the range $[0,1]$. The velocity of a particle at each dimension can be consternated to the default $v_{\text {max }}$.

The PSO algorithm is simple to compute, has fast convergence towards an optimum, easy to implement and free from the complex computation processes in genetic algorithms (e.g. crossover, mutation and coding/decoding). Nevertheless, PSO is featured with some disadvantages: limited accuracy, the algorithm will stop optimizing when it is reaching a near optimal solution, it sometimes gets trapped easily in a local optimum and in the later period of evolution, the convergence rate decreases considerably [10].

\subsection{Optimization of Quantum Particle Swarm}

The field of quantum mechanics was mainly developed. Their studies made the scientists have to rethink the traditional understanding of the nature of motions of microscopic objects and the applicability of classical mechanics [11].

Traditional PSO, a particle is determine by both location velocity vector vi and vector xi, which will be determining the particle trajectory. The particle, following Newtonian mechanics, moves long a specified trajectory. However, by considering the quantum mechanics, the expression trajectory is meaningless, because according to uncertainty principle xi and vi of a particle cannot be determined simultaneously.

Therefore, the performance of PSO will be distant from that of conventional PSO if an individual particles in a PSO system has quantum behavior [12].

In the quantum model of a PSO, the wave work $\Psi(\mathrm{x}, \mathrm{t})$ will outline the condition of a molecule rather than speed and position. The dynamic conduct of the molecule is altogether assorted from that of the molecule in established PSO frameworks.

The following iterative equations determine the particles movement:

[13], [14]:

$x(t+1)=p+\beta^{*} \mid$ mbest $-\left.x(t)\right|^{*} \ln (1 / u)$ if $k \geq$
0.5
$x(t+1)=p-\beta^{*} \mid$ mbest $-\left.x(t)\right|^{*} \ln (1 / u)$ if $k<$

$0.5 \quad(2)$ 
Where

$p=\left(c_{1} p_{i d}+c_{2} P_{g d}\right) /\left(c_{1}+c_{2}\right)$

(3)

$$
\begin{aligned}
& \text { mbest }=\frac{1}{M} \sum_{i-1}^{M} P_{i}= \\
& \left(\frac{1}{M} \sum_{i=1}^{M} P_{i 1}, \frac{1}{M} \sum_{i=1}^{M} P_{i 2}, \ldots ., \frac{1}{M} \sum_{i=1}^{n} P_{i d}\right)
\end{aligned}
$$

When the mean of the best positions of all particles, $\mathrm{u}, \mathrm{k}, \mathrm{c} 1$ and $\mathrm{c} 2$ are evenly hand out random numbers in the spacing $[0,1]$ it is mention as the Mean best (mbest) of the population. The parameter $\beta$ is represented by the term contraction-expansion coefficient. The flow chart of QPSO algorithm is shown in Figure 1.

\section{Algorithm 1}

Step1. Initialize the Swarm

Step2. Do

Step3. Calculate $\mathrm{m}$ best by equation (5).

Step4. Update particles position using equation (3).

Step5. Update p best

Step6. Update p gbest

Step7. While maximum iteration is reached

\section{Figure 1: Flow of QPSO Algorithm}

\subsection{Bees Algorithm (BA)}

The foraging artificial bees are classified by the artificial bee colony into three groups of bees: employed bees, onlookers and scouts. The employed artificial bees make the first half of the colony while the other half involves the attendant. For each nourishment source there will be only one harness bee. In other words, around the hive the number of food sources equals the number of employed bees. After the food source of an employed bee is exhausted the honey bees turns into a scout. Fig. 1 shows the pseudo-code of the algorithm, Step-by-step procedure of $\mathrm{ABC}$ is given as follows:

(a) The randomly distributed nourishment sources are created over a D-dimensional seeks space. (b) The probability value associated with the nourishment source determine the choice of an artificial attendant bee chooses for that nourishment source. $P i$, calculated by the expression:

$P_{i}$
$=\frac{f i t_{i}}{\sum_{i=1}^{N P} f i t_{i}}$

Where fit $_{i}$ is the fitness rate for dismissal $i$.

$i$ is symmetric to the nectar rate of the nourishment sources in the location $i$.

$N P$ is number of the nourishment sources.

$N P=$ No. of harness bees

In order to produce a nominee nourishment position from the old one in memory, the $\mathrm{ABC}$ uses the following term:

$V_{i j}=x_{i j}+r_{i j}\left(x_{i j}-x_{k j}\right)$

(6)

Where $k\{1,2, \ldots, \mathrm{NP}\}$ and $j\{1,2, \ldots, \mathrm{D}\}$ are randomly chosen indexes. Further, $k \neq i$ and $r_{i j}$ is a random number between $\quad[-1,1]$.

(c) In ABC algorithm, "limit" is a necessary parameter for control, it is the controller of the update times for a certain solution. The solution is called limit if no further improvement can be achieved through a predetermined number of cycles, then that dismissal is assumed as an desolate one, and the harness bee is transformed into a honey scout. If the solution is $x_{i}$ and $j \in\{1,2, \ldots, \mathrm{D}\}$ to be desolate, then a new solution produced randomly would exchange $x_{i}$ by:

$x_{i j}=x_{\min }^{j}+\operatorname{rand}(0,1)\left(x_{\max }^{j}-x_{\min }^{j}\right)$

(7)

Where $\mathrm{X}_{\text {min }}^{\mathrm{j}}$ is the lower bound of the parameter $j$ and $\mathrm{X}_{\text {max }}^{\mathrm{j}}$ is the upper bound of the parameter $j$. 


\section{3D Logistic Map}

The equation $x_{n+1}=\lambda x_{n}\left(1-x_{n}\right)$ presents the logistic map, which is the easiest chaos function. For $0<x_{n}<1 \mathrm{a}$

$\lambda=4$ the equation show the chaotic conduct.

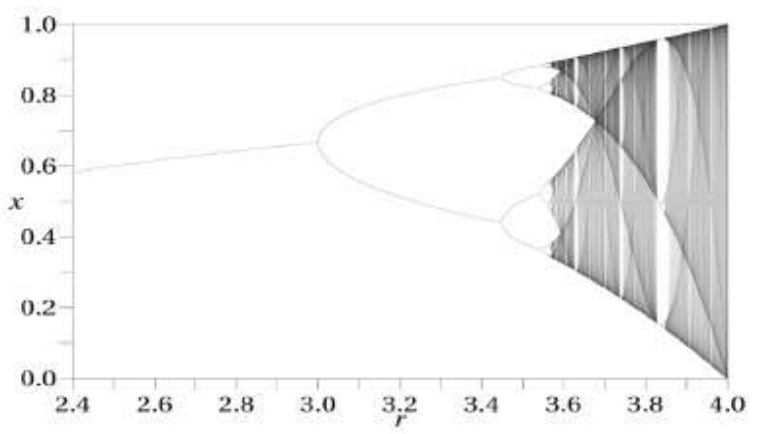

Figure2: Bifurcation diagram of logistic diagram.

Hongjuan Liu. et al suggested the two dimensional logistic map as the following shape:

$x_{i+1}=\mu_{1} x_{i}\left(1-x_{i}\right)+\gamma_{1} y_{i}^{2}$

$y_{i+1}=\mu_{2} y_{i}\left(1-y_{i}\right)+\gamma_{2}\left(x_{i}^{2}+x_{i} y_{j}\right)$

The formulas above increase the quadratic coupling of the items $y_{i}^{2}, x_{i}^{2}, x_{i} y_{i}$ and provide a more secure system. When $2.75<u_{1}<3.4,2.7<u_{2}<$ $3.45,0.15<\gamma_{1}<0.21$ and $0.13<\gamma_{2}<0.15$, the system reaches the chaotic state and be able of generating a chaotic series in the area $[0,1]$.

In this paper we expand the idea of the two dimensional Logistic map into Three-dimensional by the using the following formula:

$$
\begin{aligned}
& x_{i+1}=\lambda x_{i}\left(1-x_{i}\right)+\beta y_{i}^{2} x_{i}+\alpha z_{i}^{3}, \\
& y_{i+1}=\lambda y_{i}\left(1-y_{i}\right)+\beta z_{i}^{2} y_{i}+\alpha x_{i}^{3}, \\
& z_{i+1}=\lambda z_{i}\left(1-z_{i}\right)+\beta x_{i}^{2} z_{i}+\alpha y_{i}^{3} .
\end{aligned}
$$

The equations above show the chaotic behavior for $3.53<$ $\lambda<3.81,0<\beta<0.022,0<\alpha<0.015$ and its value can be between $[0,1]$. 


\section{The proposed Approach}

In this section, we demonstrate and explain the main phases of the proposed hybrid algorithm, figure (6).

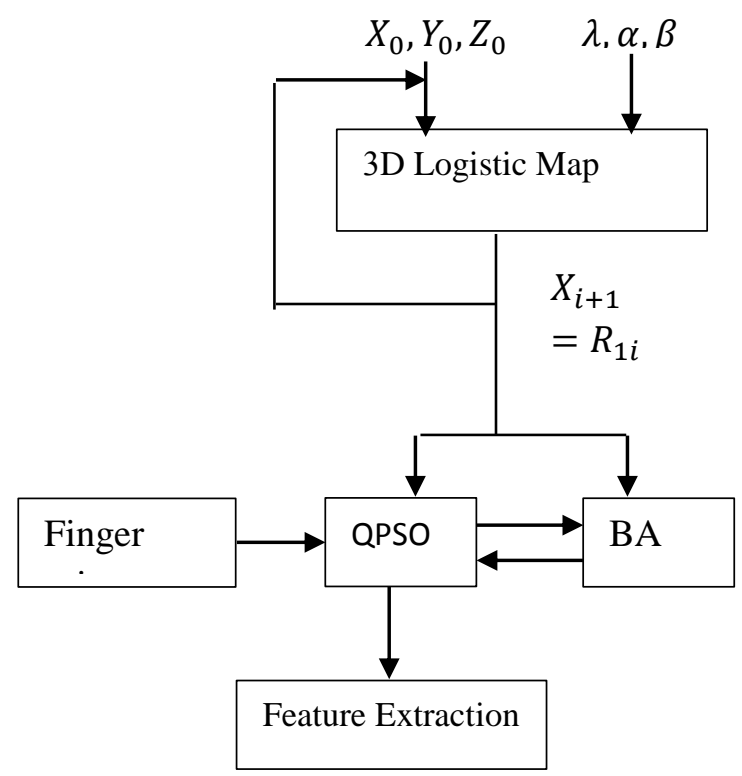

Figure 6: The proposed approach

\subsection{Initial population}

PSO, QPSO and BA algorithms working with an initial population of solutions. The food sources initial population is created by the used of the random numbers generate by 3D Logistic map owes the randomness and sensibility credence on the initialize term $\left(\mathrm{X}_{0}, \mathrm{Y}_{0}, \mathrm{Z}_{0}, \lambda, \alpha\right.$ and $\left.\beta\right)$.

\subsection{D Logistic map PSO}

3D Logistic map is implemented to improve the diversity of the particle swarm in the search space so as to avoid being trapped in local optima. In PSO, the parameter $\mathrm{w}, \mathrm{r} 1, \mathrm{r} 2$ and initial population are the key factors that affect the convergence behavior of the PSO.
The parameter $\mathrm{w}$ balances between the local search ability and the global exploration. A large inertia favors the global search, while a small inertia weight favors the local search.

In order to increase the population diversity, 3D logistic map was used to initialize the particles population and velocity.

A sequence generated by selected 3D logistic map substitutes the random parameters $\mathrm{r} 1$ and $\mathrm{r} 2$ in PSO (equation). The velocity update equation (1) for 3D logistic map PSO can be formulated as

$\mathrm{v}_{\mathrm{i}}(\mathrm{t}+1)=\mathrm{w} \quad \mathrm{v}_{\mathrm{i}}(\mathrm{t})+\mathrm{c}_{1} \quad \mathrm{R}_{1 \mathrm{i}} \quad\left(\right.$ pbest $\left.\quad \mathrm{I} \quad(\mathrm{t})-\mathrm{X}_{\mathrm{i}}(\mathrm{t})\right)+\mathrm{c}_{2}$ $\mathrm{R}_{2 \mathrm{i}}\left(\right.$ gbesti- $\left.\mathrm{X}_{\mathrm{i}}(\mathrm{t})\right)(9)$

\section{Algorithm 2}

Step1. Initializing the position and velocities of PSO

Step2. Iteration $\mathrm{t}=0$

Step3. Calculate the fitness value

Step4. Find the gbest and pbest values

Step5. Use $\mathrm{R}_{1 \mathrm{i}}$ and $\mathrm{R}_{2 \mathrm{i}}$, update position and velocities of particles.

Step6. $\mathrm{t}=\mathrm{t}+1$

Step7. stasfy the stopping condition? yes, stop. No, Go to step2.

\subsection{D Logistic map BA}

3D logistic map disturbance in introduced into basic BA, which helps bees to jump out of local optima and increases the diversity of population. The following procedures represent how this is achieved:

a- The bees are distributed in the form of circles with random diagonal $\left(\mathrm{R}_{1 \mathrm{i}}\right)$ and random angules $\left(\mathrm{R}_{2 \mathrm{i}}\right)$

b- To produce candidate food sources, the BA uses the following expression:

$v_{i j}=x_{i j}+R_{3 i}\left(x_{i j}-x_{k j}\right)$ 
Where $\mathrm{k}$ and $\mathrm{j}$ are randomly chosen indexes $\left(\mathrm{k}=\mathrm{R}_{1 \mathrm{i}}\right.$ and $\mathrm{j}=\mathrm{R}_{2 \mathrm{i}}$ ).

c- The scout honey bee period of the calculation utilizes the equation:

$x_{i j}=x_{t b}+R_{3 i}\left(R_{1 i}-R_{2 i}\right)$

(11)

Where $\mathrm{x}$ is the best of these individuals.

\subsection{D Logistic map QPSO}

Random parameters in particle motion equations (2, 3 and 4) will be replaced by random parameters generator (3D logistic map) to be as follows:

$x(t+1)=$

$P+\beta^{*} \mid$ mbest $-x(t) \mid * \operatorname{Ln}\left(\frac{1}{R_{1}}\right)$ if $R_{2} \geq 0.5$

$x(t+1)=$

$P-\beta^{*} \mid$ mbest $-x(t) \mid * \operatorname{Ln}\left(\frac{1}{R_{1}}\right)$ if $R_{2}<0.5$ (12)

Where

$P=\left(R_{2} P_{i d}+R_{3} P_{g d}\right) /\left(R_{2}+R_{3}\right)$

mbest $=\frac{1}{M} \sum_{i=1}^{M} P_{j}$

\subsection{Hybrid Approach}

From the discussion above of PSO, BA and QPSO, it is clearly noticed that global best solution of the population is being straight used in Bee algorithm, and concurrently, it is possible to conclude that if the particles in the PSO is stuck in the local minima, the local minima may not lost by it. To overcome the shortage points of these two algorithms, our proposal is a hybrid global optimization approach combines BA and QPSO searching mechanism based on 3D logistic map.

The following procedure is the hybrid algorithm procedure:

\section{Algorithm 3}

Step 1: Initialize particles position, velocities and initial population of food source $x_{i, i}=1, \ldots S_{n}$ by
3D logistic map (equation 8) and initialize the parameters of this algorithm, such as maximum iteration, the population of particles and so on.

Step 2 The (mbest) of each particle is computed by equation (14).

Step 3: Determining the numbers of bees that are distributed.

Step 4: Finding the global for QPSO algorithm based on the bees as follows:

4-1 Evaluate each food source

4-2 Choose circles with random diameters and random angles based on Step 1 and Step 3.

4-3 Using 3D logistic BA algorithm: Evaluation and extraction of the best equation of bees based on scout (equation11), which represents an assessment of the global for the QPSO algorithm.

Step 5: QPSO algorithm equation (12, 13 and 14) are applied.

Step 6: the iteration should be checked and see if it reached the maximum iteration. If so, the algorithm is stopped, output the result, otherwise return to step 2 .

\section{Implementation test results}

The proposed method is applied on several fingerprint images in order to test two proposed methods (PSO and Hybrid Approach), the main characteristic is to specify unique feature for each fingerprint that will help in the identification algorithm. A dataset of 20 fingerprint grayscale images was taken for the experiment result as shown in figure 7 of size $100 * 100$ pixel. In the proposed method was chosen as a considered starting point and then find the best points that are connected by using similar methods and excluding the points, the results have been shown that the second algorithm (Hybrid Approach) produces similar points less than the first method (PSO). The results points will used to extract feature such as mean, standard deviation or average angles with starting point. 


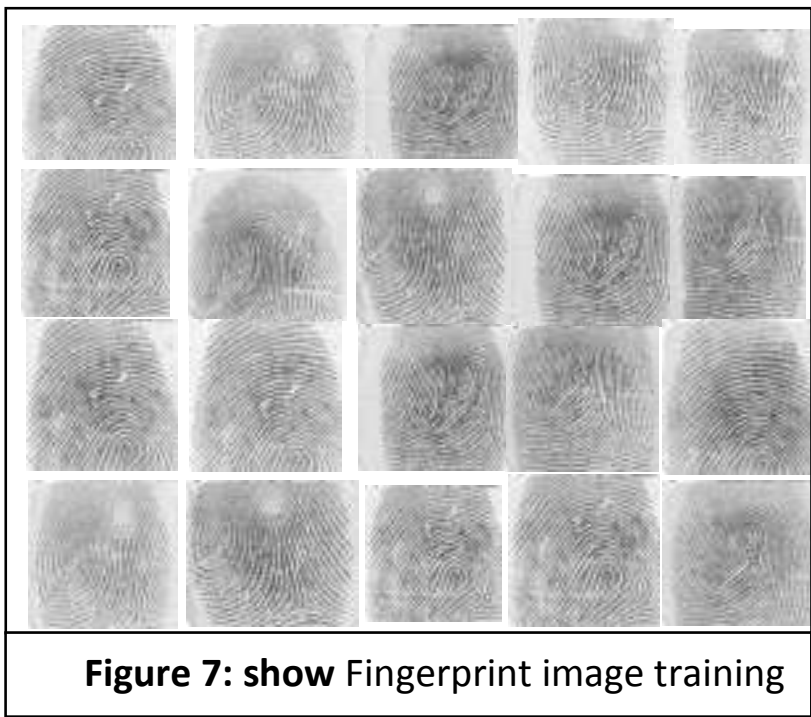

The mean of extracted point was find in different iteration $(20,40,60,80$ or 100$)$ for first starting point $(50,50)$ as shown in tables 1 and 2 and in figures 8 and 9 for PSO and Hybrid approaches respectively, while tables 3 and 4 for another starting point (55, 55), and in figures 10 and 11, also for PSO and Hybrid Approaches respectively.

Table 1: PSO feature 1 of starting point $(50,50)$ mean

\begin{tabular}{|c|c|c|c|c|c|}
\hline Mean & $\begin{array}{l}\text { Iterati } \\
\text { on }=20\end{array}$ & $\begin{array}{l}\text { Iteration } \\
=40\end{array}$ & $\begin{array}{l}\text { Iteration= } \\
60\end{array}$ & $\begin{array}{l}\text { Iteration } \\
=80\end{array}$ & $\begin{array}{l}\text { Iterati } \\
\text { on }=10 \\
0\end{array}$ \\
\hline Image 1 & $\begin{array}{l}142.8 \\
000\end{array}$ & $\begin{array}{l}135.075 \\
0\end{array}$ & 137.9167 & $\begin{array}{l}139.050 \\
0\end{array}$ & $\begin{array}{l}140.4 \\
100 \\
\end{array}$ \\
\hline Image 2 & $\begin{array}{l}180.9 \\
500\end{array}$ & $\begin{array}{l}178.475 \\
0\end{array}$ & 181.7167 & $\begin{array}{l}182.550 \\
0\end{array}$ & $\begin{array}{l}175.2 \\
500\end{array}$ \\
\hline Image 3 & $\begin{array}{l}170.5 \\
500 \\
\end{array}$ & $\begin{array}{l}179.250 \\
0 \\
\end{array}$ & 180.2500 & $\begin{array}{l}177.675 \\
0\end{array}$ & $\begin{array}{l}180.0 \\
500 \\
\end{array}$ \\
\hline Image 4 & $\begin{array}{l}138.6 \\
000\end{array}$ & $\begin{array}{l}141.825 \\
0\end{array}$ & 162.1500 & $\begin{array}{l}161.950 \\
0\end{array}$ & $\begin{array}{l}162.3 \\
100\end{array}$ \\
\hline Image 5 & $\begin{array}{l}192.4 \\
000\end{array}$ & $\begin{array}{l}199.825 \\
0\end{array}$ & 200.3667 & $\begin{array}{l}201.475 \\
0\end{array}$ & $\begin{array}{l}200.7 \\
500 \\
\end{array}$ \\
\hline
\end{tabular}

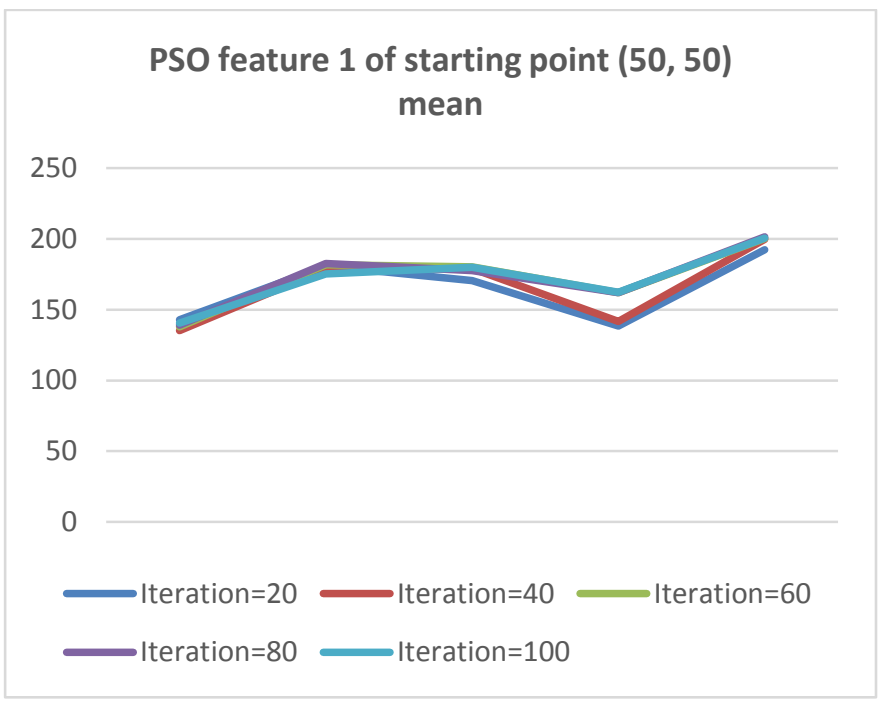

Figure 8: show PSO feature 1 of starting point (50, 50) mean

Table 2: Hybrid Approach feature 1 of starting point $(50,50)$ mean

\begin{tabular}{|l|l|l|l|l|l|}
\hline Mean & iteration =20 & $\begin{array}{l}\text { Iteration } \\
=\mathbf{4 0}\end{array}$ & $\begin{array}{l}\text { iteration } \\
=60\end{array}$ & $\begin{array}{l}\text { Iteratio } \\
\mathbf{n}=\mathbf{8 0}\end{array}$ & $\begin{array}{l}\text { Iteration } \\
=100\end{array}$ \\
\hline image 1 & $\mathbf{1 3 1 . 1 5 5 4}$ & $\mathbf{1 3 3 . 6 2 5 3}$ & $\mathbf{1 4 4 . 4 8 3 3}$ & $\begin{array}{l}\mathbf{1 4 7 . 5 0 1} \\
\mathbf{2}\end{array}$ & $\mathbf{1 4 8 . 8 7 6}$ \\
\hline image 2 & 163.6543 & 165.3757 & 159.6167 & $\begin{array}{l}157.325 \\
6\end{array}$ & 159.113 \\
\hline image 3 & 148.1232 & 158.9432 & 165.3667 & $\begin{array}{l}168.537 \\
5\end{array}$ & 171.024 \\
\hline image 4 & 146.0534 & 147.2545 & 160.4833 & $\begin{array}{l}158.462 \\
5\end{array}$ & 158.415 \\
\hline image 5 & 195.0575 & 200.1100 & 199.1333 & $\begin{array}{l}201.762 \\
5\end{array}$ & 203.334 \\
& & & & & \\
\hline
\end{tabular}




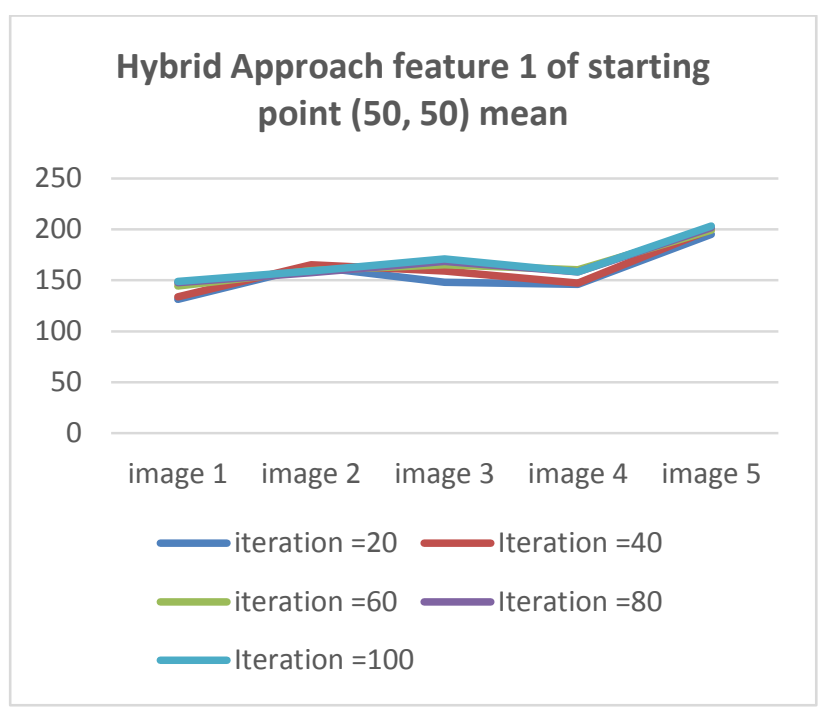

Figure 9: Hybrid Approach feature 1 of starting point $(50,50)$ mean

Table 3: PSO feature 1 of starting point $(55,55)$ mean

\begin{tabular}{|l|l|l|l|l|l|}
\hline Mean & $\begin{array}{l}\text { Iteration } \\
=20\end{array}$ & $\begin{array}{l}\text { Iteration=4 } \\
0\end{array}$ & $\begin{array}{l}\text { Iteration=6 } \\
0\end{array}$ & $\begin{array}{l}\text { Iteration=8 } \\
0\end{array}$ & $\begin{array}{l}\text { Iteration } \\
=100\end{array}$ \\
\hline Image 1 & $\begin{array}{l}142.730 \\
0\end{array}$ & 135.0810 & 137.9179 & 139.0480 & $\begin{array}{l}140.436 \\
0\end{array}$ \\
\hline Image 2 & 180.870 & 178.5250 & 181.7187 & 182.6000 & $\begin{array}{l}175.147 \\
0\end{array}$ \\
\hline Image 3 & $\begin{array}{l}170.480 \\
0\end{array}$ & 179.2300 & 180.2460 & 177.7250 & $\begin{array}{l}180.065 \\
0\end{array}$ \\
\hline Image 4 & $\begin{array}{l}138.590 \\
0\end{array}$ & 141.7950 & 162.1540 & 161.9670 & $\begin{array}{l}162.327 \\
0\end{array}$ \\
\hline Image 5 & $\begin{array}{l}192.430 \\
0\end{array}$ & 199.8650 & 200.3747 & 201.5370 & $\begin{array}{l}200.820 \\
0\end{array}$ \\
\hline
\end{tabular}

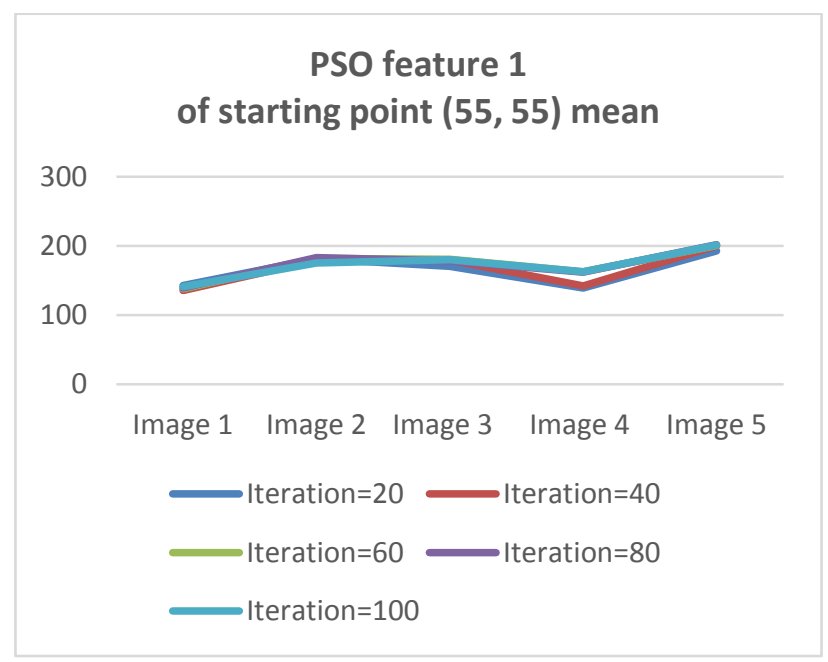

Figure 10: show PSO feature 1 of starting point $(55,55)$ mean
Table 4: Hybrid Approach feature 1 of starting point $(55,55)$ mean

\begin{tabular}{|l|l|l|l|l|l|}
\hline Mean & $\begin{array}{l}\text { Iteration } \\
=20\end{array}$ & $\begin{array}{l}\text { Iteration } \\
=40\end{array}$ & $\begin{array}{l}\text { Iteration } \\
=60\end{array}$ & $\begin{array}{l}\text { Iteration } \\
=80\end{array}$ & $\begin{array}{l}\text { Iteration } \\
=100\end{array}$ \\
\hline Image 1 & 131.1554 & 133.6258 & 144.4833 & 147.5900 & 148.8791 \\
\hline Image 2 & 163.6545 & 165.3756 & 159.6137 & 157.3230 & 159.1144 \\
\hline Image 3 & 148.1110 & 158.9870 & 165.3667 & 168.5375 & 171.0223 \\
\hline Image 4 & 146.0555 & 147.2510 & 160.4855 & 158.4655 & 158.4198 \\
\hline Image 5 & 195.0543 & 200.0100 & 199.1333 & 201.7625 & 203.3788 \\
\hline
\end{tabular}

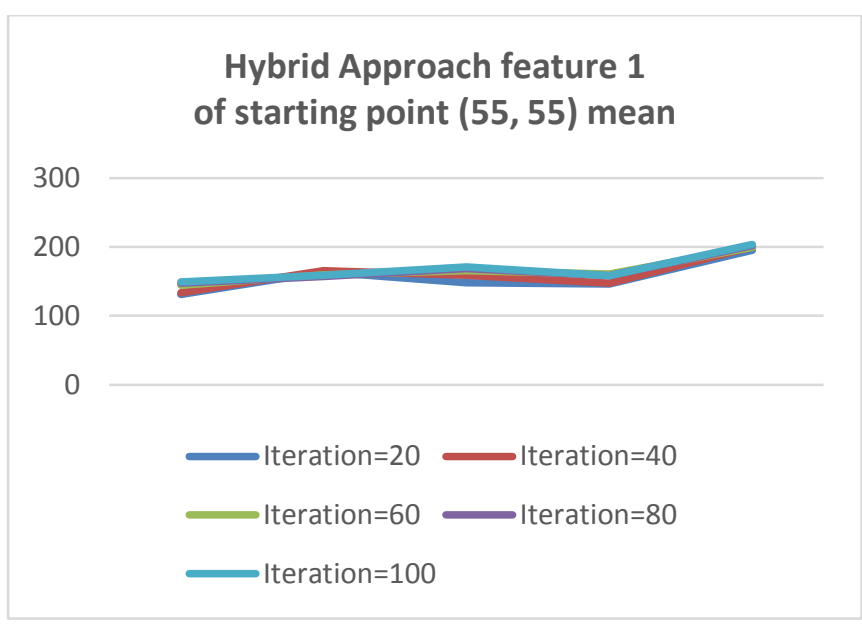

Figure 11 shows Hybrid Approach feature 1 of starting point $(55,55)$ mean

The second feature extracted from resulted point is average angles that calculate for each point with respect to starting point all point make different angle and the average will be unique for each fingerprint image as shown in tables 5, 6 and in figures 12 and 13 for 20,40,60,80 and 100 iteration with starting point $(50,50)$ with implementation PSO and Hybrid Approach respectively. In the same way applied with another starting point $(55,55)$ in tables 7 and 8 , and in figures 14 and 15 respectively. 
Table 5: PSO feature 2 of starting point $(50,50)$ average angles

\begin{tabular}{|l|l|l|l|l|l|}
\hline Mean & $\begin{array}{l}\text { Iteration } \\
=20\end{array}$ & $\begin{array}{l}\text { Iteration=4 } \\
0\end{array}$ & $\begin{array}{l}\text { Iteration=6 } \\
0\end{array}$ & $\begin{array}{l}\text { Iteration=8 } \\
0\end{array}$ & $\begin{array}{l}\text { Iteration } \\
=100\end{array}$ \\
\hline $\begin{array}{l}\text { Image } \\
1\end{array}$ & 0.52710 & 0.20843 & 0.03445 & -0.19694 & - \\
\hline $\begin{array}{l}\text { Image } \\
2\end{array}$ & - & -0.10376 & -0.06015 & -0.07471 & $\begin{array}{l}- \\
0.22096\end{array}$ \\
\hline $\begin{array}{l}\text { Image } \\
3\end{array}$ & 0.54487 & & & & 0.00089 \\
\hline $\begin{array}{l}\text { Image } \\
4\end{array}$ & 0.14038 & -0.25425 & 0.09479 & 0.35095 & 0.45672 \\
\hline $\begin{array}{l}\text { Image } \\
5\end{array}$ & - & -0.23617 & -0.28143 & -0.30368 & - \\
\hline
\end{tabular}

PSO feature 2 of starting point $(50,50)$ average angles

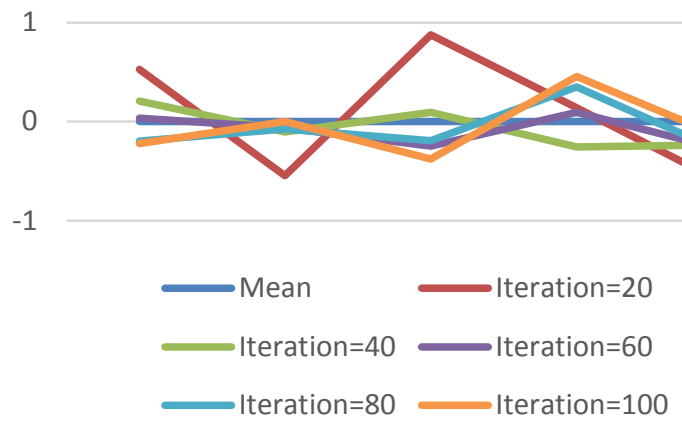

Figure 12: show PSO feature 2 of starting point $(50,50)$ average angles

Table 6: Hybrid Approach feature 2 of starting point

\section{$(50,50)$ average angles}

\begin{tabular}{|l|l|l|l|l|l|}
\hline $\begin{array}{l}\text { Average } \\
\text { Angle }\end{array}$ & $\begin{array}{l}\text { Iteration= } \\
20\end{array}$ & $\begin{array}{l}\text { Iteration= } \\
40\end{array}$ & $\begin{array}{l}\text { Iteration= } \\
60\end{array}$ & $\begin{array}{l}\text { Iteration= } \\
80\end{array}$ & $\begin{array}{l}\text { Iteratio } \\
\mathrm{n}=100\end{array}$ \\
\hline Image 1 & -1.05694 & -1.04692 & -1.02748 & -0.95303 & $\begin{array}{l}- \\
0.8595 \\
9\end{array}$ \\
\hline Image 2 & 0.25383 & -0.16956 & -0.17439 & -0.27869 & $\begin{array}{l}- \\
0.3737 \\
5\end{array}$ \\
\hline Image 3 & -0.01869 & -0.12877 & -0.12432 & -0.04539 & $\begin{array}{l}0.0425 \\
1\end{array}$ \\
\hline Image 4 & -0.83227 & -0.02578 & 0.24624 & 0.34578 & $\begin{array}{l}0.4078 \\
7\end{array}$ \\
\hline Image 5 & 0.09159 & 0.00348 & 0.24458 & 0.16342 & $\begin{array}{l}0.1373 \\
0\end{array}$ \\
\hline
\end{tabular}

Hybrid Approach feature 2 of starting point $(50,50)$ average angles

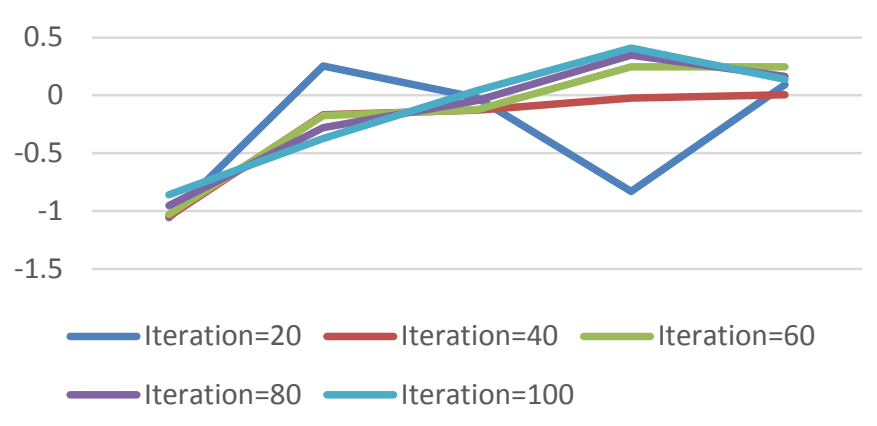

Figure 13: show Hybrid Approach feature 2 of starting point $(50,50)$ average angles

Table 7: PSO feature 2 of starting point $(55,55)$ average angles

\begin{tabular}{|l|l|l|l|l|l|}
\hline $\begin{array}{l}\text { Average } \\
\text { Angle }\end{array}$ & $\begin{array}{l}\text { Iteration } \\
=20\end{array}$ & $\begin{array}{l}\text { Iteration } \\
=40\end{array}$ & $\begin{array}{l}\text { Iteration } \\
=60\end{array}$ & $\begin{array}{l}\text { Iteration } \\
=80\end{array}$ & $\begin{array}{l}\text { Iteration } \\
=100\end{array}$ \\
\hline Image 1 & $\begin{array}{l}0.26745 \\
0.34837\end{array}$ & $\begin{array}{l}- \\
0.16041\end{array}$ & 0.31074 & 0.37548 \\
\hline Image 2 & 0.19831 & 0.01512 & 0.01813 & 0.07122 & 0.12862 \\
\hline Image 3 & - & - & - & - & - \\
& 0.34662 & 0.76078 & 0.68865 & 0.31802 & 0.04468 \\
\hline Image 4 & - & - & - & - & - \\
& 0.34827 & 0.75642 & 0.88170 & 0.84762 & 0.91650 \\
\hline Image 5 & 0.50919 & 0.26187 & 0.06474 & - & - \\
& & & & 0.01890 & 0.16497 \\
\hline
\end{tabular}

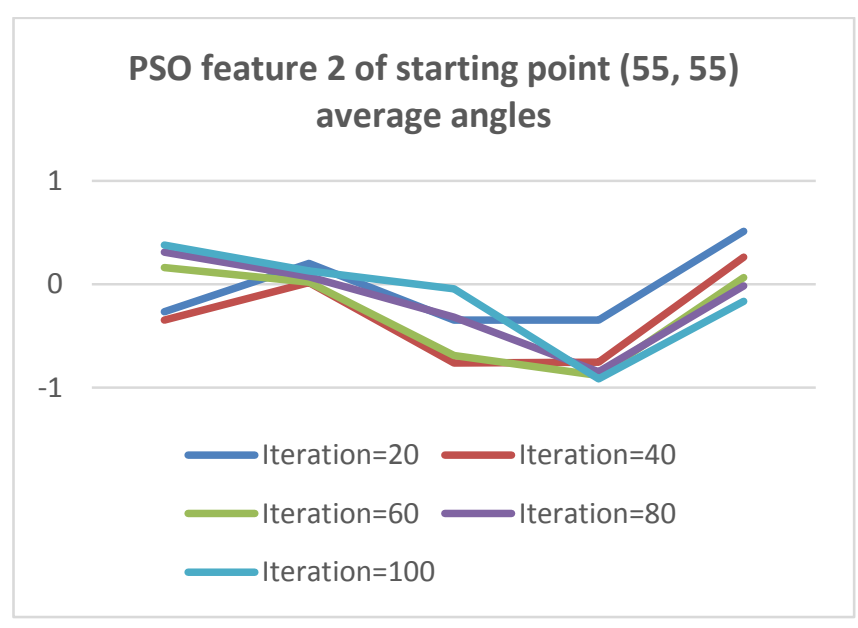

Figure 14: show PSO feature 2 of starting point $(55,55)$ average angles 
Table 8: Hybrid Approach feature 2 of starting point $(55,55)$ average angles

\begin{tabular}{|l|l|l|l|l|l|}
\hline $\begin{array}{l}\text { Average } \\
\text { Angle }\end{array}$ & $\begin{array}{l}\text { Iteration= } \\
20\end{array}$ & $\begin{array}{l}\text { Iteratio } \\
\mathrm{n}=40\end{array}$ & $\begin{array}{l}\text { Iteration= } \\
60\end{array}$ & $\begin{array}{l}\text { Iteration= } \\
80\end{array}$ & $\begin{array}{l}\text { Iteration= } \\
100\end{array}$ \\
\hline Image 1 & 0.46490 & $\begin{array}{l}- \\
0.0021 \\
3\end{array}$ & -0.23676 & -0.35045 & -0.49429 \\
\hline Image 2 & -0.46758 & $\begin{array}{l}0.2721 \\
2\end{array}$ & 0.43779 & 0.40692 & 0.39469 \\
\hline Image 3 & 0.12344 & $\begin{array}{l}0.6130 \\
0\end{array}$ & 0.67102 & 0.63927 & 0.64633 \\
\hline Image 4 & -0.30820 & $\begin{array}{l}0.0714 \\
4\end{array}$ & 0.15083 & -0.19837 & -0.24251 \\
\hline Image 5 & 1.11319 & $\begin{array}{l}0.7655 \\
4\end{array}$ & 0.65123 & 0.41054 & 0.27524 \\
\hline
\end{tabular}

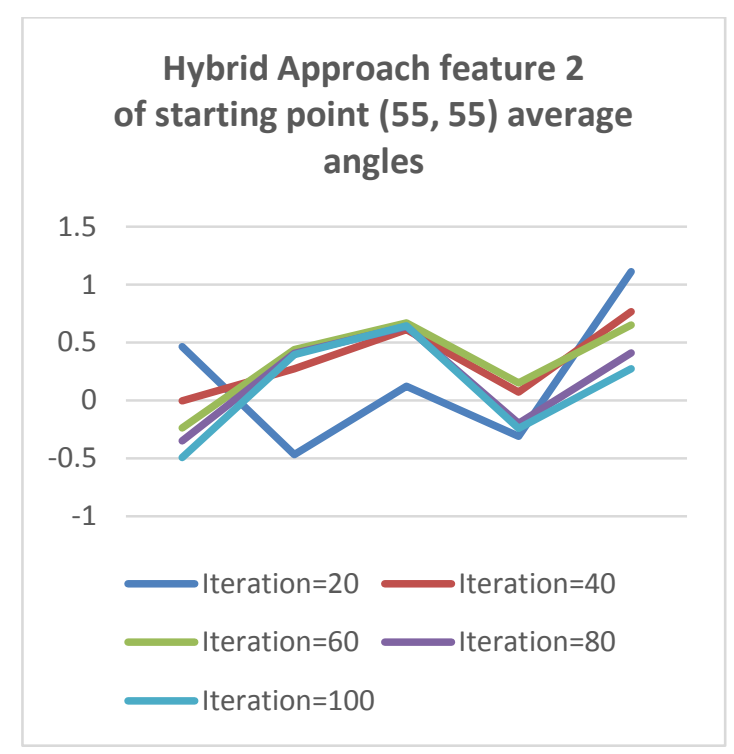

Figure 15: show Hybrid Approach feature 2 of starting point $(55,55)$ average angles

The above tables and graphs showed comparisons between the proposed algorithm with the PSO algorithm and various random elementary sites. The comparison was made in terms of the method of finding feature extraction. The proposed algorithm was based on the angle of the starting points and in all cases the results were much better than the PSO algorithm

\section{Conclusion}

The PSO used for selection related point to starting point in fingerprint these points will used for feature extraction. A dynamic parameter adjustment is used in the Hybrid Approach algorithms, which is conductive in order to jump out of local optima and move to global extreme the results indicate that the improved algorithm for ability of solving and can solve in a better method the global optimum to asset the requirement of accuracy. The result is explained that all features are unique to corresponding fingerprint image. The number of iteration are used for controlling the complexity of algorithm.

\section{References}

[1] Liu J, Sun J, Xu W, Quantum-Behaved Particle Swarm Optimization with Adaptive Mutation Operator. ICNC 2006, Part I, Springer-Verlag: 959 - 967, 2006.

[2] Liu J, Xu W, Sun J. Quantum-Behaved Particle Swarm Optimization with Mutation Operator. In Proc. of the $17^{\text {th }}$ IEEE Int. Conf. on Tools with Artificial Intelligence, Hong Kong (China), 2005.

[3] Mohammed EL-Abd,"On the hybridization of the artificial bee colony and particle swarm optimization algorithm", JAISCR, 2012,vol.2,No.2,PP.147-155.

[4] Noosheen B. and Mohammed R. Meybodi, "A New hybrid Model of PSO and $\mathrm{ABC}$ algorithm for optimization in Dynamic Environment ", International Journal of computer theory and Engineering, vol.4,Noo.3,2012.

[5] Wang chum- feng, Linkui, and shen peiping,"Hybrid Artificial Be colony Algorithm and particle swarm search for global optimization, Mathematical problems in Engineering vol.2014(2014), Article ID832914,8 pages. 
[6] Oguz Altum and Tarik K.,"Particle swarm optimization - Artificial Bee colony chain (OSOABC): A Hybrid metheahuristic Algorithm", $\mathrm{SCl}$, workshops on Electric and computer Engineering subfields, Koc University, Istanbul/ Turkey ,2014.

[7] Juan A.Lozzus, Marco R. and carlos H.Lopez-carabalio ,"parameter estimation of loren $\mathrm{z}$ chaotic system using a hybrid swarm intelligence algorithm", physics Letter A vol.380,Issues 11-12,2016,page 1160-1171.

[8] Tarun K.sharma and millie pant, "Improved swarm Bee algorithm for global

optimization",iRAFIT 2012, proceedings published in international Journal of computer Applications (IJCA).

[9] J.Kennedy, R.C.Eberahart, Particle swarm optimization, IEEE International Conference on Neural Networks, Perth, WA., (1995), 1942-1948.

[10] X. Yang, J.Yuan, H.Mao, A modified particle swarm optimization with dynamic adaption, Journal of Applied Mathematics and Computation, 186, (2007), 1205-1213.
[11] Pang XF, Quantum mechanics in nonlinear systems. River Edge (NJ, USA): World Scientific Publishing Company, 2005.

[12] Bin Feng, Wenbo Xu, Adaptive Particle Swarm Optimization Based on Quantum Oscillator Model. In Proc. of the 2004 IEEE Conf. on Cybernetics and Intelligent Systems, Singapore: 291 - 294, 2004.

[13] Sun J, Feng B, Xu W, Particle Swarm Optimization with particles having Quantum Behavior. In Proc. of Congress on Evolutionary Computation, Portland (OR, USA), 325 - 331, 2004.

[14] Sun J, Xu W, Feng B, A Global Search Strategy of Quantum-Behaved Particle Swarm Optimization. In Proc. Of the 2004 IEEE Conf. on Cybernetics and Intelligent Systems, Singapore: 291 - 294, 2004.

[15] Pham D.T., Ghanbarzadeh A., Koc E., Otri S., and Zaidi M., 2006. "The Bees Algorithm-A Novel Tool for Complex Optimization Problems", in second Virtual International Conference on Intelligent Production Machines and Systems (IPROMS 2006), Elsevier. Cardiff, UK. pp: 454-459. 
استخراج خصائص البصمه بأستخدام نهج هجين :خوارزمية اسراب الطيور الكمية و النحل بالاعتماد على خريطة لوجستية ذو بعد ثلاثي

نور حيدر عبد الامير

الجامعة التكنولوجية /قسم علوم الحاسوب

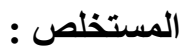

خوارزمية اسراب الطيور من السهل فيها الوصول إلى التقارب المبكرة في عملية الحل، وأيضا تقع في الحل الأمثل المحلي. خوارزمية النحل هي ذات الاستدلال الأمثل على أساس سلوك العلف لنحل العسل. وقد تم التأكد من أن هذه الخوارزمية قادرة على البحث عن الأمثل العالمي، ولكن هناك عيب واحد، انها حقيقة أن أفضل حل عالمي لا يستخدم بطريقة مباشرة، ولكن خوارزمية النحل تخزنها لكل التكرار. نقترح نهجا هجينا جديدا من أجل معالجة هذه المشاكل، فإنه بين خوارزمية ال QPSO وخوارزمية BA على أساس 3D خريطة لوجستية. من ناحية، يتم استخدام خريطة لوجستية 3D لتهيئة الجزيئات موز عة موحدة وذلك لتعزيز نوعية السكان الأولية، وهي طريقة فعالة جدا ولكن بسيطة لتحسين نوعية السكان الأولي. من ناحية أخرى فإن جو هر هذا النهج هو استخدام QPSO للحصول على القيمة المثلى للسكان في BA. بعد تحديد نقطة الانطلاق في الخوارزمية الجديدة، يكون شكل التوزيع من الدو ائر ذات الزوايا العشو ائية والقطرية العشوائية حيث تولد الخريطة اللوجستية ثلاثية الأبعاد الأرقام العشو ائية. تم تطبيق الخوارزمية لاستخر اج خصائص البصمة، وكانت النتائج بالمقارنة مع خوارزمية PSO التقليدية ممتازة.

الكلمات المفتاحية : خوارزمية اسراب الطيور ، خوارزمية النحل ، الخريطة اللوجستية ذو البعد الثلاثي ، لمثل

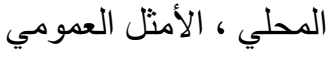

